\title{
Centrality of Shame Memories and Psychopathology: The Mediator Effect of Self-Criticism
}

\author{
José Pinto-Gouveia ${ }^{1}$, M.D., Ph.D. \\ Paula Castilho ${ }^{1}$, Ph.D. \\ Marcela Matos ${ }^{1}$, Ph.D. \\ Ana Xavier ${ }^{1}$, MSc., Ph.D. Student \\ ${ }^{1}$ Cognitive-Behavioural Research Centre (CINEICC), University of Coimbra, Portugal \\ * Correspondence concerning this article should be addressed to: \\ Paula Castilho \\ CINEICC, Faculdade de Psicologia e Ciências da Educação, Universidade de Coimbra \\ Rua do Colégio Novo, Apartado 6153 \\ 3001-802 Coimbra, Portugal \\ Telefone: (+351) 239851450 \\ Fax: $(+351) 239851462$ \\ E-mail: paulacastilho@fpce.uc.pt
}




\begin{abstract}
Research has shown that the centrality of shame memories is related to psychopathological symptoms. However, little is known about the role of self-criticism on this association. The current study explored a mediator model in which self-criticism was hypothesized to mediate the relationship between centrality of shame memories and depressive symptoms, and between centrality of shame memories and paranoid beliefs. A battery of self-report instruments measuring centrality of shame memory (CES), forms (FSCRS) and functions (FSCS) of self-criticism, depressive symptoms (DASS42) and paranoid beliefs (GPS) was administered to 204 participants from the general community population. Results showed that centrality of shame memories played an important role in depressive symptoms and paranoid beliefs. Only in depression that measures of self-criticism acted as a mediator between centrality of shame and depressive symptomatology. These findings point out to the distinct role that selfcriticism plays on the relationship between shame memories and depressive and paranoid symptoms, adding to current evolutionary approaches on these two psychopathological features.

Keywords: Self-criticism; Centrality of shame memories; Depression; Paranoia; Mediator effect
\end{abstract}




\section{Centrality of Shame Memories and Psychopathology:}

\section{The Mediator Effect of Self-Criticism}

Two psychopathogical pervasive disorders that correspond to evolved responses specifically linked to social hierarchies are depression and paranoia. According to an evolutionary approach, depression is an involuntary defeat strategy that may arise from loss or reductions in one's perceived ability to compete for social place (e.g., being rejected by a lover or for a job, feeling inferior to others because of personal qualities), or when one fails in the struggle for important biosocial goals (e.g., be chosen as a friend, lover, team member). So, depression is linked to being in an involuntary subordinate position, and to feelings of helplessness, powerlessness, and entrapment (Price, Sloman, Gardner, Gilbert, \& Rohdem, 1994; Seligman, 1991Sloman, Gilbert, \& Hasey, 2003).

Paranoia, also related to social fears, is associated with in-group social rank whereby dominants can threaten and injury subordinates. The evolutionary role of paranoia is then linked to its usefulness to detect threats to the self from potentially harmful others using the 'better safe than sorry' conditional rule (Gilbert, 1998, 2001; Gilbert, Boxall, Cheung, \& Irons, 2005). Paranoid individuals tend to believe others hold negative intentions towards them and want to harm them. This leads to their generally suspiciousness and distrust of others, which produces interpersonal difficulties.

Although depression and paranoia have for long been the focus of interest in the scientific community, it crucial to better understand the processes through which adverse experiences in early life may contribute to the development of depressive and paranoid symptoms. 
Shame experiences are early negative interactions that have been linked to depressive and paranoid symptomatology (Matos \& Pinto-Gouveia, 2010; Matos, PintoGouveia, \& Gilbert, 2012; Pinto-Gouveia \& Matos, 2011). Shame is primarily related to the experience of the self as existing negatively in the minds of the others as an unattractive social agent (Gilbert, 1998, 2003), and is also accompanied by a selffocused and self-evaluative experience of the self as inferior, defective, inadequate, worthless or powerless in some way (Kaufman, 1989; Gilbert, 1998; Tangney \& Fisher, 1995; Tracy \& Robins, 2004). Given that shame entails a major threat to the social self, shame memories can be seen as threat-activating memories that operate like emotional hot-spots in the mind (Kaufman, 1989; Gilbert, 2003). So, shame experiences, such as criticism from a parent, being rejected by a lover, bullying, failing at something important, being sexually or physically abused, can be recorded in autobiographical memory as conditioned emotional memories. These threat memories have a powerful impact on self-schema, emotional and attentional processing and on neurophysiologic systems (Baumeister, Bratslavsky, Finkenauer, \& Vohs, 2001; Dickerson \& Kemeny, 2004; Gilbert, 2003; Schore, 1998, 2001).

A recent study showed that shame memories from childhood and adolescence can function like traumatic memories, with intrusion, avoidance, and hyperarousal symptoms (Matos \& Pinto-Gouveia, 2010). They can become central to one's identity and life story (Pinto-Gouveia \& Matos, 2011; Matos \& Pinto-Gouveia, 2011). So, in the light of the centrality of event theory (Berntsen \& Rubin, 2006, 2007), shame memories that are construed as traumatic and central autobiographical memories, can operate as self-defining memories in the self-memory system (Conway, 2005; Conway \& PleydellPearce, 2000; Matos, Pinto-Gouveia, \& Costa, 2011; Singer \& Salovey, 1993) in that they give meaning and continuity to one's sense of self and life story (McAdams, 2001; 
McAdams, Josselson, \& Lieblich, 2006) and influence behaviour and goals (Sutin \& Robins, 2008). In addition, a central trauma memory can form a highly available reference point for the organization of autobiographical knowledge, influencing subsequent attentional, emotional, and cognitive processing (Berntsen \& Rubin, 2006, 2007). Moreover, these shame memories may lead to internal working models of self (e.g., as being defective, inferior, and so on, and negatively evaluated by others) and others (e.g. as critical, threatening, hostile, who may criticize, reject, exclude or harm the self) that influence emotional and social responses to negative self-defining events (Baldwin \& Dandeneau, 2005; Mikulincer \& Shaver, 2005; Matos, Pinto-Gouveia, \& Costa, 2011). Recent studies have shown that these shame traumatic and central memories are associated with depression and paranoia (Matos \& Pinto-Gouveia, 2010, 2011; Matos, Pinto-Gouveia, \& Gilbert, 2012; Pinto-Gouveia, \& Matos, 2011).

Self-criticism is associated with a process of internal shaming (Gilbert, 2005, 2007a) and may be rooted in shaming experiences in childhood (Castilho, PintoGouveia, \& Coelho, 2011). So, according to attachment theory (Mikulincer \& Shaver, 2005), the degree in which people are able to access warm and supportive or condemning and critical other-to-self and self-to-self memories has a central role on emotional and social responses to events (Baldwin \& Dandeneau, 2005; Blatt \& Homann, 1992; Gilbert, 2005; Koestner, Zuroff, \& Powers, 1991; Thompson \& Zuroff, 1999). When things go wrong and one becomes critical of oneself, one can feel defeated and depressed by self-criticism - a kind of self-harassment into depression (Gilbert, 1989; Greenberg, Elliott, \& Foerster, 1990; Gilbert, Clarke, Hempel, Miles, \& Irons, 2004; Gilbert, Baldwin, Irons, Baccus, \& Palmer, 2006; Whelton \& Greenberg, 2005). Self-criticism can then be pathogenic when it is linked to powerful negative emotions of anger and disgust directed at the self and to an inability to activate self- 
soothing systems in face of failures or setbacks (Gilbert, 2000, 2006; Gilbert et al., 2004).

Thus, self-criticism is now known to be a major prospective vulnerability trait for depression (Blatt, 2004; Hartlage, Arduino, \& Alloy, 1998; Gilbert et al., 2001; Gilbert et al., 2006; Rector, Bagby, Segal, Joffe, \& Levitt, 2000; Teasdale et al., 2001; Zuroff, Koestner, \& Powers, 1994) and to be associated with paranoid beliefs (Mills, Gilbert, Bellew, McEwan, \& Gale, 2007).

Both depression and paranoia are associated with social rank dynamics, although with distinct evolutionary functions. While depression operates as an involuntary defeat strategy and may constitute a damage limitation strategy when facing loss or social defeat, paranoia is related to protection against attacks from dominant. The primary purpose of this study is then to explore whether early shame experiences and selfcriticism, both linked to the social rank system, has a differential impact on these two psychopathological symptoms and whether shame experiences contribute to depressive and paranoid symptoms through their impact on self-criticism. It was predicted that individuals who recall their shame memories as more central to their identity and life story would show higher levels of self-criticism, depressive symptoms, and paranoid beliefs. Furthermore, this study explores the mediator effect of self-criticism on the relationship between centrality of shame memories and depressive symptoms and paranoid beliefs. It was hypothesized that self-criticism would mediate the emotion regulation process in the relationship between centrality of shame memories and depressive symptoms and between centrality of shame memories and paranoid beliefs. This would mean that shame memories central to one's identity operate through selfcriticism on depressive symptoms and paranoid beliefs. 


\section{Method}

\section{Participants and Procedure}

Participants in this study were 204 subjects from the general Portuguese community population. Seventy one per cent were females $(n=144)$ and $29.4 \%$ males $(n=60)$. The mean age was $36.06(S D=10.22)$. Concerning marital status, $55.8 \%$ of the participants were married or in a relationship $(n=114), 36.3 \%$ were single $(n=74)$, $6.4 \%$ were divorced $(n=13)$ and $1.5 \%$ were widows $(n=3)$. Fifty nine per cent of the subjects have middle class professions $(n=120)$. The mean participants years of education was $13.34(S D=3.54)$.

This convenience sample was recruited in the Districts of Coimbra, Viseu, and Aveiro in the middle region of Portugal. A battery of self-report questionnaires was administered to participants, within the staff of institutions, namely schools and private corporations. These institution's boards were contacted, the research aims were clarified and authorization was obtained so that their employees could participate in the study. Afterwards, the participants were elucidated about the investigation goals and invited to voluntarily participate. Then, self-report questionnaires were complete by volunteers in the presence of the researcher. In line with ethical requirements, it was emphasized that participants cooperation was voluntary and that their answers were confidential and only used for the purpose of the study, and participants gave their informed consent. (Did they provide written consent? If so, please indicate. If not, please add a sentence saying this is the ethically accepted (by whom, e.g., we have APA ethical guidelines) and standard procedure for ethical research in Portugal.

\section{Measures}




\section{Self-Criticism}

Forms of Self-Criticizing/attacking and Self-Reassuring Scale (FSCRS; Gilbert, Clarke, Hempel, Miles, \& Irons, 2004; Portuguese version by Castilho \& PintoGouveia, 2011). The FSCRS is a 22-item scale designed to examine how people think about themselves when things go wrong for them. It measures how critical/attacking or how supportive/reassuring people are themselves. To the first probe statement: 'When things go wrong for me...' participants respond on a 5-point Likert scale (ranging from $0=$ not at all like me, to $4=$ extremely like me) on series of questions (e.g. "I am easily disappointed with myself'). This scale is comprises three subscales: 1) inadequate self, which captures a sense of feeling internally put-down and rendered inadequate by failures and setbacks (e.g. "I think I deserve my self-criticism"); 2) hated self, which captures a more destructive, disgust-based response to setbacks (rather than inadequate) characterized by self-dislike and an aggressive/sadistic/persecuting desire to hurt the self (e.g. "I have become so angry with myself that I want to hurt or injure myself"); 3) reassured self, which indicated a positive warm disposition to the self, characterized by self-reassuring before failures and setbacks (e.g. "I still like being me"). In this study inadequate self and hated self were used as a total score of self-criticism as suggested by Gilbert, Baldwin, Irons, Baccus, and Palmer (2006). In the original study, the Cronbach's alpha of the subscales were .90 for inadequate self, and .86 for hated self and .86 for reassured self (Gilbert et al., 2004). The composite score for self-criticism (the sum of inadequate and hated self subscales) also revealed a good internal consistency (Cronbach's alpha $=.91$; Gilbert et al., 2006).

Functions of Self-Criticizing/attacking Scale (FSCS; Gilbert, Clarke, Hempel, Miles, \& Irons, 2004; Portuguese version by Castilho \& Pinto-Gouveia, 2011). The 
FSCS assesses the reasons/functions people have for self-attacking. Following a probe statement, 'I get critical and angry with myself', there are 21 questions reflecting possible reasons for self-attacking. Participants respond on a 5-point Likert scale (ranging from $0=$ not at all like me, to $4=$ extremely like me). Items include: "to make sure I keep my standards up", through to more persecuting and self-harm reasons of "to destroy part of me". The original factor analysis revealed two factors that correspond to two functions of self-criticism: self-correcting, when people fear they might become inadequate or lazy unless, they keep criticizing themselves and coercing themselves into action; self-attacking/persecuting, denotes a level of aggression to the self, which is about hurting and taking revenge at the self. In this study, only self-attacking was used. In the original study, the Cronbach's alpha of both subscales was .92 (Gilbert et al., 2004).

\section{Centrality of shame memories}

Centrality of Event Scale (CES; Berntsen \& Rubin, 2006; Portuguese version by Matos, Pinto-Gouveia, \& Gomes, 2011) measures the extent to which a memory of a stressful event forms a reference point for personal identity and for the attribution of meaning to other experiences in a person's life. This self-report questionnaire consists of 20 items, rated on 5-point scales $(1=$ Totally disagree; $5=$ Totally agree $)$ that assess the three interdependent characteristics of highly negative emotional memories: Reference points for everyday inferences (e.g. "This event has colored the way I think and feel about other's experiences."), turning points in life stories (e.g. "I feel that this event has become a central part of my life story.") and components of personal identity (e.g. "I 
feel that this event has become part of my identity."). In its original study, a high internal consistency (Cronbach's alpha=.94) was obtained for the total CES score.

Priming for a shame memory:

In this study, we modified the instructions of the CES to prime participants with a shame memory and complete the scale with that memory as their focus. Participants were instructed to answer the questionnaire based on a significant and stressful shame experience they recalled from their childhood or adolescence, considering the following instructions:

"The experience of shame is common among all human beings and everyone, throughout life, has shame experiences. We know now that these are important experiences that might be related to several problems in people's lives. In this questionnaire we are interested in getting to know your shame experiences, that is, a situation where you felt shame. Shame is a negative self-conscious emotion associated to a feeling of inferiority and personal devaluation.

Now, please try to recall a (significant) situation or experience in which you think you felt shame, during your childhood and/or adolescence. Please think back upon that significant shame event in your life and answer the following questions in an honest and sincere way, by circling a number from 1 to 5 ."

This adjustment in the instructions priming for a shame memory has been made in other studies (Matos, Pinto-Gouveia \& Duarte, 2012; Pinto-Gouveia \& Matos, 2011;) and it doesn't seem to affect the validity of the measure since the items' content is well suited for both instructions and the internal reliability for the total score of the CES was excellent in both studies (Cronbach' alpha $=.96$ ). 


\section{Depression}

Depression, Anxiety and Stress Scales (DASS-42; Lovinbond \& Lovinbond, 1995; Portuguese version by Pais-Ribeiro, Honrado, \& Leal, 2004) is a self-report measure of 42 items and designed to assess three dimensions of psychopathological symptoms: depression, anxiety, and stress. The items indicate negative emotional symptoms, and the respondents are asked to rate each item on a 4-point scale (0-3). In the original version, Lovibond and Lovibond (1995) found the subscales to have high internal consistency (depression subscale Cronbach's $\alpha=.91$; anxiety subscale Cronbach's $\alpha=.84$; stress subscale Cronbach's $\alpha=.90$ ). In the present research, only the depression subscale of the DASS-42 was used.

\section{Paranoia}

General Paranoia Scale (GPS) was developed by Fenigstein and Vanable (1992) and translated and adapted into Portuguese by Lopes and Pinto-Gouveia (2005). This 20-item self-report is the most widely used dimensional measure of paranoia (Freeman et al., 2005). The GPS was designed to measure paranoia in college students, particularly, the following characteristics: the belief that another person, or a powerful external influence, is commanding the individual's thoughts and behaviors (e.g., "Someone has been trying to influence my mind"); the belief of a conspiracy against oneself, i.e. others are working together to conspire against the individual (e.g., "My parents and family find more fault in me than they should."); the belief of being spied on and talked negatively about oneself behind one's back (e.g., "I sometimes feel as if I am being followed."); a general suspicion regarding others and a lack of trust on people (e.g., "It is safer to trust no one.") and finally the presence of feelings of resentment (e.g., "I am sure I get a raw deal from life."). Each item is rated on a 5-point Likert 
scale (1-5). Scores can range from 20 to 100, with higher scores indicating greater paranoid ideation. Fenigstein and Vanable (1992) found this scale to have good internal consistency across their four North-American samples (Cronbach' $\alpha=.84)$. The Portuguese version of the GPS reported an excellent internal reliability (Cronbach' $\alpha$ $=.92$; Lopes \& Pinto-Gouveia, 2005).

\section{Statistical analyses}

Three analyses were conducted to investigate the relationships between centrality of shame memories, self-criticism and psychopathology. The study was conducted within a cross sectional design with self-reports measures.

In the first analysis, centrality of shame memories was considered the predictor variable and Depression, as measured by DASS Depression subscale, was considered the dependent variable. Self-criticism was assessed using FSCRS and FSCS, which were hypothesized to be mediator variables.

In the second analysis, centrality of shame memories was the predictor and paranoia, as measured by GPS, was the dependent variable. Self-criticism, measured by FSCRS, and self-attacking, measured by FSCS, were hypothesized to be mediators.

Pearson correlation coefficients were performed to explore the relationships between predictor variables, outcome variables, and the mediators.

Linear regression models were used to test the effects of the mediator on each dependent variable, following Baron and Kenny (1986) procedures. Sobel Test was further performed to determine the significance of the indirect effect of the predictor variable on outcome, through its effects on the mediator. The mediation (full or partial) suggested by the regression model is significant if Sobel z is $p<.050$ (Preacher \& Leonardelli, 2010). 


\section{Results}

\section{Preliminary Data Analyses}

A series of tests were conducted to examine the suitability of the current data for regression analyses. We performed an analysis of residuals scatter plots since it provides a test of assumptions of normality, linearity and homoscedasticity between dependent variables scores and errors of prediction. Our data showed that the residuals were normally distributed, had linearity and homoscedasticity. Also, the independence of the errors was analyzed and validated through graphic analysis and the value of Durbin-Watson (values ranged between 1.663 and 2.220). No evidence of the presence of multicollinearity or singularity amongst the variables was found. These aspects were validated by the Variance Inflation Factor (VIF) values that indicated the absence of $\beta$ estimation problems $(V I F<5)$. In general, the results indicate that these data are adequate for regression analyses.

\section{Descriptives}

The means, standard deviations and Cronbach alphas for all variables are presented on Table 1. All scales showed good to very good internal consistencies. No significant differences were found for gender. Therefore, all statistical analyses were conducted with the total sample.

(Table 1 about here) 


\section{Centrality of Shame Memory, Self-Criticism, and Depressive symptoms}

\section{Correlations}

Pearson correlation coefficients were performed to explore the association between self-criticism, centrality of shame memory, and depression (see Table 2). Centrality of shame memory was significantly correlated with depression and moderately associated with self-criticism (FSCRS) and self-attacking (FSCS). Finally, self-criticism (FSCRS and FSCS) showed moderate correlations with depression.

(Table 2 around here)

The Mediator Effect of Self-Criticism on the Relationship between Centrality of Shame Memory and Depression

Recent research has shown that centrality of shame memory is related to depression, even when the effect of current feelings of shame are controlled for; it also moderates the effect of shame on depressive symptoms (Pinto-Gouveia \& Matos, 2011; Matos \& Pinto-Gouveia, 2011). Furthermore, self-criticism constitutes an important vulnerability factor for depression (Blatt \& Zuroff, 1992; Gilbert \& Irons, 2004). These findings taken together with our data, led us to hypothesize that self-criticism might function as a mediator variable on the relationship between centrality of shame memory and depression.

To test for this mediator effect we followed the 4-step mediator analysis procedure recommended by Baron and Kenny (1986) (see Table 3). In the first regression analysis, centrality of shame memory produced a significant model in the prediction of depression, $F_{(1,202)}=14.82, p \leq .001$, accounting for $6 \%$ of the variance $(\beta$ $=.26, p \leq .001)$. The next regression analysis was significant, with centrality of shame 
memory explaining $10 \%$ of self-criticism (FSCRS), $F_{(1,202)}=22.91, p \leq .001$. Finally, when centrality of shame memory and self-criticism (FSCRS) were entered as independent variables to predict depression, the model was significant, $F_{(2,201)}=30.75$, $p \leq .001$, and accounted for $23 \%$ of variance. Regression coefficients analysis showed that when the mediator is added in, the predictor $\beta$ is reduced to .12 and is no longer significant, suggesting the existence of a full mediator effect of self-criticism (FSCRS). The Sobel Test showed that this indirect effect was significant $(z=3.89, p \leq .001)$.

Similar analyses were performed to examine the mediator effect of self-attacking (FSCS) on the relationship between centrality of shame memory and depression (see Table 3). The first regression model was significant as reported above. In the next regression, centrality of shame memory produced a significant model in the prediction of self-attacking $(\mathrm{FSCS}), F_{(1,202)}=24.45, p \leq .001$. In the final model, centrality of shame memory and self-attacking (FSCS) accounted for 17\% of depression variance, $F_{(2,201)}=21.97, p \leq .001$. Results showed that when self-attacking (FSCS) is added in the model, the predictor $\beta$ is reduced to .15 and its significance level is less expressive $(p=.033)$, pointing to the existence of a partial mediator effect. The Sobel Test was significant $(z=3.64, p \leq .001)$, indicating that self-attacking (FSCS) partially mediates the effect of centrality of shame memory on depression.

(Table 3 about here)

\section{Centrality of Shame Memories, Self-Criticism and Paranoia}

\section{Correlations}


We explored the relations between self-criticism (FSCRS), self-attacking function (FSCS), centrality of shame memory, and paranoia. Pearson correlation coefficients showed that self-criticism (FSCRS) and self-attacking (FSCS) were significantly associated with paranoia. Also, centrality of shame memory was significantly related to paranoia (see Table 2).

The Mediator Effect of Self-Criticism on the Relationship between Centrality of Shame Memory and Paranoia

We hypothesized that self-criticism and self-attacking could function as mediator variable on the relationship between centrality of shame memory and paranoia. To examine these mediator effects the same procedures described above were performed (see Table 4).

In the first regression, centrality of shame memory accounted for $15 \%$ of paranoia, $F_{(1,202)}=35.57, p \leq .001$. The next model was also significant with centrality of shame memory explaining $10 \%$ of self-criticism. In the last regression analysis, centrality of shame memory and self-criticism produced a significant model, $F_{(2,201)}=$ 41.83, $p \leq .001$, and it emerged as significant global predictors of paranoia. Thus, no mediator effect of self-criticism was found.

Similar procedures were conducted to explore the mediator effect of selfattacking (Table 4). As reported above, the first model was significant. In the next regression, centrality of shame memory produced a significant model in the prediction of self-attacking. In the final model, centrality of shame memory and self-attacking (FSCS) accounted for $22 \%$ of paranoid beliefs variance, $F_{(2,201)}=28.86, p \leq .001$. Results showed that when the self-attacking (FSCS) was added in the model, both the predictor and the mediator emerged as significant in the prediction of the outcome 
variable. Thus, no mediator effect was found since both centrality of shame memories and self-attacking have independent effects to the variance of paranoid beliefs.

\section{Discussion}

There are empirical and clinical evidence suggesting that shame memories that function as traumatic and central memories to one's identity and life story are associated with psychopathological symptoms (Matos \& Pinto-Gouveia, 2010, 2011; PintoGouveia \& Matos, 2011; Matos, Pinto-Gouveia, \& Gilbert, 2012). Additionally, selfcriticism is an important process in the development and maintenance of psychopathology (Cheung, Gilbert, \& Irons, 2004; Gilbert et al., 2006; Gilbert, Boxall, Cheung, \& Irons, 2005). This study explored the relationship between centrality of shame memories, self-criticism, and depressive symptoms and paranoid beliefs.

Results showed that centrality of shame memories was significantly correlated with self-criticism and self-attacking. So, individuals whose shame memories operate as anchoring events for their sense of self-identity tend to engage in self-critical processing styles and to use self-criticism to harm or hurt the self for failures. These data are in line with our prediction and with previous work showing that early exposure to threats, in the form of abuse, neglect, parental criticism, rejection and overprotection may be translated into forms of self-devaluation, self-condemnation and self-critical/attacking feelings and cognitions (Blatt \& Zuroff, 1992; Gilbert \& Irons, 2004; Gilbert et al., 2004; Parker, 1983; Perris, 1994; Schore, 1994). Furthermore, early shame experiences, where one is criticized, shamed, abused, or rejected, function as central reference points to one's identity, and may be internalized in negative internal working models about the self (e.g. as being defective, inferior, and so on, and negatively evaluated by others). 
They may increase the vulnerability to self-criticism as an emotional self-regulation strategy associated with negative defensive self-directed emotions (e.g. anger, disgust, shame) and behaviors (e.g. submission, avoidance, appeasement) (Baldwin, 2005; Baldwin \& Dandeneau, 2005; Castilho et al., 2011; Gilbert et al., 2006; Mikulincer \& Shaver, 2005, 2007; Pinto-Gouveia \& Matos, 2011).

Centrality of shame memory was significantly correlated with depressive symptoms and self-criticism and self-attacking. Self-criticism was also associated with depressive symptoms and paranoid beliefs. These findings are consistent with previous studies that found centrality of shame memory and self-criticism were related to psychopathological symptoms, such as depression (Gilbert et al. 2004; Gilbert et al., 2006; Pinto-Gouveia \& Matos, 2011; Whelton \& Greenberg, 2005) and paranoia (Matos et al., 2012; Mills et al., 2007).

Given the prior empirical evidence, we tested for the mediator effect of selfcriticism on the relationship between centrality of shame memories and depressive symptoms and between centrality of shame memories and paranoid beliefs. We found that self-criticism and self-attacking mediated the association between centrality of shame memories and depressive symptoms. Thus, it seems that centrality of shame memories are related to depressive symptoms through their relation to self-criticism and self-attacking. In contrast, for paranoia, no mediator effect of self-criticism and selfattacking was found. This means that centrality of shame memories has an independent contribution to paranoid beliefs that is not explained by the effect of self-criticism.

Why, then, is self-criticism a mediator for depression and not for paranoia? One possible explanation for these findings might be that these shame memories may function as self-defining memories in the self-memory system and comprise self-to-self schemas (e.g. self-critical, self-attacking) (Baldwin \& Dandeneau, 2005). By becoming 
highly accessible and easily primed emotional memories, they may influence the emergence of a self-critical processing style. In turn, self-criticism, as an inner rehearsal of attack-submit interaction, may trigger involuntary defeat responses, i.e., depressive symptoms (Gilbert et al., 2004; Gilbert et al., 2006; Whelton \& Greenberg, 2005; Gilbert, 2007a). However, for paranoia, it might be that when these shame memories integrate interpersonal schemas (e.g. where others are perceived as threatening, critical and hostile) they may contribute to believe others hold malevolent intentions toward the self (e.g. others may harm, reject, exclude or persecute the self). Given that paranoia is linked to external threats to self-identity, the effect of centrality of shame memories seems to be independent and not mediated by internalizing shame processes, such as self-criticism. Therefore, in paranoia, shame memories seem to be a key to perceive others as threatening and hostile, whereas in depression, a much more internalizing disorder, these emotional memories seem to operate through self-criticism.

\section{Clinical implications}

The present study may contribute to a better understanding of the role of selfcriticism on the relationship between centrality of shame memories and psychopathology.

Some therapeutic implications might be drawn from our findings since, despite our having used a nonclinical sample; the same mechanisms and processes involving shame memories and self-criticism may apply at a clinical or nonclinical level. Thus, the results emphasize the relevance of assessing and working with self-criticism, not only when helping individuals' depressive symptoms but also when they suffer from paranoid ideation (Gilbert, 2006, 2007b, 2010; Gilbert \& Irons, 2005; Gilbert \& Procter, 2006). In addition, the data underline the importance of addressing and reconstructing 
the meaning associated with shame memories, in patients experiencing paranoid symptoms and in those with depressive symptoms for whom self-criticism may emerge as a self-regulating process to deal with negative defensive outputs associated with shame memories (Gilbert, 2010; Robinson, 1996; Robinson \& Taylor, 1998).

\section{Limitations \& Future research}

One methodological limitation of the current study is its the cross-sectional design which does not allow for strong conclusions to be drawn about a developmental sequence or trajectory that unfolds over time. In the future, prospective studies would improve the understanding of the causal relations between the variables. The low number of males in the current sample constitutes another possible limitation that might be related to the degree of depressive and paranoid symptoms in the sample. This may limit the generalization of the results to more heterogeneous populations. Future studies should replicate these findings using more representative samples in regard to sociodemographic variables.

Because this study was conducted in a general community sample, the findings cannot be generalized to clinical populations; we are currently replicating this study using a clinical sample. Finally, we did not control for the type of shame memory that was elicited and, in the future, structured interviews, such as the Shame Experience Interview (Matos \& Pinto-Gouveia, 2006), could be administered to assess the phenomenology of early shame experiences. However, CES scores have been similar to those found in studies controlling for the type of shame memory (Matos \& PintoGouveia, 2011; Matos, Pinto-Gouveia, \& Duarte, 2011).

Nonetheless, this is the first study to show that self-criticism might function as a mediator on the association between centrality of shame memories and depressive 
symptoms in a general population. This empirically supports the idea that those individuals whose shame memories become central to identity and life story and have a critical and attacking self-to-self relation, tend to present more depressive symptoms. Conversely, the effect of centrality of shame memories on paranoid beliefs seems to be independent and not explained by self-criticism. 


\section{References}

Baldwin, M. W. (Ed.) (2005). Interpersonal cognition. New York: Guilford Press.

Baldwin, M. W., \& Dandeneau, S. D. (2005). Understanding and modifying the relational schemas underlying insecurity. In M. W. Baldwin (Ed.), Interpersonal cognition (pp. 33-61). New York: Guilford.

Baron, M., \& Kenny, D. (1986). The moderator-mediator variable distinction in social psychological research: Conceptual, strategic, and statistical considerations. Journal of Personality and Social Psychology, 51, 1173-1182. doi: http://dx.doi.org/10.1037//0022-3514.51.6.1173

Baumeister, R. F., Bratslavsky, E., Finkenauer, C., \& Vohs, K. D. (2001). Bad is stronger than good. Review of General Psychology, 5, 323-370. doi: http://dx.doi.org/10.1037//1089-2680.5.4.323

Berntsen, D., \& Rubin, D. C. (2006). Centrality of event scale: A measure of integrating a trauma into one's identity and its relation to post-traumatic stress disorder symptoms. Behaviour Research and Therapy, 44, 219-231. doi:10.1016/j.brat.2005.01.009

Berntsen, D., \& Rubin, D. C. (2007). When a trauma becomes a key to identity: Enhanced integration of trauma memories predicts posttraumatic stress disorder symptoms. Applied Cognitive Psychology, 21, 417-431. doi:10.1002/acp.1290.

Blatt, S. J. (2004). Experiences of depression: Theoretical, clinical, and research perspectives. Washington, DC: American Psychological Association.

Blatt, S. J., \& Homann, E. (1992). Parent-child interaction in the etiology of dependent and self-critical depression. Clinical Psychology Review, 12, 47-91. doi: http://dx.doi.org/10.1016/0272-7358(92)90091-L 
Blatt, S., \& Zuroff, D. (1992). Interpersonal relatedness and self-definition: Two prototypes for depression. Clinical Psychology Review, 12, 527-562. doi: http://dx.doi.org/10.1016/0272-7358(92)90070-O

Castilho, P., \& Pinto-Gouveia (2011). The Portuguese version of the Forms of SelfCriticizing/Attacking and Self-Reassuring Scale and Functions of SelfCriticizing/Attacking Scale: Psychometric properties. (Manuscript in preparation)

Castilho, P., Pinto-Gouveia, \& Coelho, S. (2011). Recall of threat and submissiveness in childhood and self-criticism: The mediator effect of internal shame. (Manuscript in preparation)

Cheung, M., Gilbert, P., \& Irons, C. (2004). An exploration of shame, social rank and rumination in relation to depression. Personality and Individual Differences, 36, 1143-1153. doi: http://dx.doi.org/10.1016/S0191-8869(03)00206-X

Conway, M. A. (2005). Memory and the self. Journal of Memory and Language, 53, 594-628. doi: http://dx.doi.org/10.1016/j.jml.2005.08.005

Conway, M. A., \& Pleydell-Pearce, C. W. (2000). The construction of autobiographical memories in the self-memory system. Psychological Review, 107, 261-288. doi: http://dx.doi.org/10.1037//0033-295X.107.2.261

Dickerson, S. S., \& Kemeny, M. E. (2004). Acute stressors and cortisol response: A theoretical integration and synthesis of laboratory research. Psychological Bulletin, 130, 335-391. doi: http://dx.doi.org/10.1037/0033-2909.130.3.355

Fenigstein, A., \& Vanable, P. A. (1992). Paranoia and self-consciousness. Journal of Personality and Social Psychology, 62, 129-138. doi: http://dx.doi.org/10.1037//0022-3514.62.1.129

Freeman, D., Garety, P. A., Bebbington, P. E., Smith, B., Rollinson, R., Fowler, D., Kuipers, E., Ray, K., \& Dunn, G. (2005). Psychological investigation of the 
structure of paranoia in a non-clinical population. British Journal of Psychiatry, 186, 427-435. doi: http://dx.doi.org/10.1192/bjp.186.5.427

Gilbert, P. (1989). Human nature and suffering. London: Lawrence Erlbaum Associates.

Gilbert, P. (1998). What is shame? Some core issues and controversies. In P. Gilbert \& B. Andrews (Eds.), Shame: Interpersonal behaviour, psychopathology and culture (pp. 3-36). New York: Oxford University Press.

Gilbert, P. (2000). Social mentalities: Internal 'social' conflicts and the role of inner warmth and compassion in cognitive therapy. In P. Gilbert \& K. G. Bailey (Eds.), Genes on the couch: Explorations in evolutionary psychotherapy (pp. 118-150). Hove: Psychology Press.

Gilbert, P. (2001). Evolutionary approaches to psychopathology: The role of natural defences. Australian and New Zealand Journal of Psychiatry, 35, 17-27. doi: http://dx.doi.org/10.1046/j.1440-1614.2001.00856.x

Gilbert, P. (2003). Evolution, social roles and the differences in shame and guilt. Social Research, 70, 1205-1230.

Gilbert, P. (2005). Compassion and cruelty: A biopsychosocial approach. In P. Gilbert (Ed.), Compassion: Conceptualisations, research and use in psychotherapy (pp. 974). London: Routledge.

Gilbert, P. (2006). A biopsychosocial and evolutionary approach to formulation with a special focus on shame. In N. Tarrier (Ed.), Case formulation in cognitive behaviour therapy: The treatment of challenging and complex cases (pp. 81-112). Hove: Routledge. 
Gilbert, P. (2007a). The evolution of shame as a marker for relationship security. In J.

L. Tracy, R. W. Robins, \& J. P. Tangney (Eds.), The self-conscious emotions: Theory and research (pp. 283-309). New York: Guilford.

Gilbert, P. (2007b). Evolved minds and compassion in the therapeutic relationship. In N. P. Gilbert, \& R. Leahy (Eds.), The therapeutic relationship in the cognitive behavioural psychotherapies (pp. 106-142). Hove: Routledge.

Gilbert, P. (2010). Compassion focused therapy: Distinctive features. London: Routledge.

Gilbert, P., Baldwin, M. W., Irons, C., Baccus, J. R., \& Palmer, M. (2006). Selfcriticism and self-warmth: An imagery study exploring their relation to depression. Journal of Cognitive Psychotherapy: An International Quarter, 20 (2), 183-200. doi: http://dx.doi.org/10.1891/jcop.20.2.183

Gilbert, P., Birchwood, M., Gilbert, J., Trower, P., Hay, J., Murray, B., \& Miles, J. N. V. (2001). An exploration of evolved mental mechanisms for dominant and subordinate behaviour in relation to auditory hallucinations in schizophrenia and critical thoughts in depression. Psychological Medicine, 31, 1117-1127. doi: http://dx.doi.org/10.1017/S0033291701004093

Gilbert, P., Boxall, M., Cheung, M., \& Irons, C. (2005). The relation of paranoid ideation and social anxiety in a mixed clinical population. Clinical Psychology and Psychotherapy, 12, 124-133. doi: http://dx.doi.org/10.1002/cpp.438

Gilbert, P., Clarke, M., Hempel, S., Miles, J. N. V., \& Irons, C. (2004). Criticizing and reassuring oneself: An exploration of forms, styles and reasons in female students. The British Journal of Clinical Psychology, 43, 31-50. doi: http://dx.doi.org/10.1348/014466504772812959 
Gilbert, P., \& Irons, C. (2004). A pilot exploration of the use of compassionate images in a group of self-critical people. Memory, 12, 507-516. doi: http://dx.doi.org/10.1080/09658210444000115

Gilbert, P., \& Irons, C. (2005). Focused therapies and compassionate mind training for shame and self-attacking. In P. Gilbert (Ed.), Compassion: Conceptualisations, research and use in psychotherapy (pp. 263-325). London: Routledge.

Gilbert, P., \& Procter, S. (2006). Compassion mind training for people with high shame and self-criticism: Overview and pilot study. Clinical Psychology and Psychology, $13,353-379$.

Greenberg, L. S., Elliott, R. K., \& Foerster, F. S. (1990). Experiential processes in the psychotherapeutic treatment of depression. In C. D. McCann \& N. S. Endler (Eds.), Depression: New directions in theory, research, and practice (pp. 157185). Toronto: Wall and Emerson.

Hartlage, S., Arduino, K., \& Alloy, L. B. (1998). Depressive personality characteristics: state dependent concomitants of depressive disorder and traits independent of current depression. Journal of Abnormal Psychology, 107, 349-354. doi: http://dx.doi.org/10.1037//0021-843X.107.2.349

Kaufman, G. (1989). The psychology of shame. New York: Springer.

Koestner, R., Zuroff, D. C., \& Powers, T. A. (1991). Family origins of adolescent selfcriticism and its continuity into adulthood. Journal of Abnormal Psychology, 100, 191-197. doi: http://dx.doi.org/10.1037//0021-843X.100.2.191

Lopes, B., \& Pinto-Gouveia, J. (2005). Portuguese version of the 'General Paranoia Scale'. (Unpublished manuscript)

Lovinbond, P., \& Lovinbond, H. (1995). The structure of negative emotional states: Comparison of the depression anxiety stress scales (DASS) with beck depressive 
and anxiety inventories. Behaviour Research and Therapy, 3, 335-343. doi: http://dx.doi.org/10.1016/0005-7967(94)00075-U

Matos, M., \& Pinto-Gouveia, J. (2006). Shame Experiences Interview. Unpublished manuscript

Matos, M., \& Pinto-Gouveia, J. (2010). Shame as a Traumatic Memory. Clinical Psychology and Psychotherapy, 17, 299-312. doi: 10.1002/cpp.659

Matos, M., \& Pinto-Gouveia, J. (2011). Centrality of shame memory as a moderator on the relationship between shame and depression. (Submitted manuscript).

Matos, M., Pinto-Gouveia, J. \& Costa, V. (2011). Understanding the importance of attachment in shame traumatic memory relation to depression: The impact of emotion regulation processes. Clinical Psychology and Psychotherapy. doi: 10.1002/cpp.786

Matos, M., Pinto-Gouveia, J., \& Duarte, C. (2012). Above and beyond emotional valence: The unique contribution of the central and traumatic shame memories to psychopathology vulnerability. Memory, 20 (5), 461-477. doi:

$10.1080 / 09658211.2012 .680962$

Matos, M., Pinto-Gouveia, J., \& Duarte, C. (2011). Other as Shamer: Portuguese version and psychometric properties of an external shame measure (Submitted manuscript).

Matos, M., Pinto-Gouveia, J., \& Gilbert, P. (2012). The effect of shame and shame memories on paranoid ideation and social anxiety. Clinical Psychology and Psychotherapy. doi: 10.1002/cpp.1766

Matos, M., Pinto-Gouveia, J., \& Gomes, P. (2010). A Centralidade das Experiências de Vergonha: Estudo de validação da versão portuguesa da Escala da Centralidade do Acontecimento. Psicologia, XXIV, 73-95. 
McAdams, D. P. (2001). The psychology of life stories. Review of General Psychology, 5, 100-122. doi: http://dx.doi.org/10.1037//1089-2680.5.2.100

McAdams, D. P., Josselson, R., \& Lieblich, A. (Eds.). (2006). Identity and story: Creating self in narrative. Washington, DC: APA Books.

Mikulincer, M., \& Shaver, P. (2005). Mental representations of attachment security: theoretical foundations for a positive social psychology. In M. W. Baldwin (Ed.), Interpersonal cognition (pp. 233-266). New York: Guilford.

Mikulincer, M., \& Shaver, P. (2007). Attachment in adulthood structure, dynamics and change. The Guilford Press.

Mills, A., Gilbert, P., Bellew, R., McEwan, K., \& Gale, C. (2007). Paranoid beliefs and self-criticism in students. Clinical Psychology and Psychotherapy, 14, 358-364. doi: http://dx.doi.org/10.1002/cpp.537

Pais-Ribeiro, J., Honrado, A., \& Leal, I. (2004). Contribuição para o estudo da adaptação portuguesa das escalas de ansiedade, depressão, stress de Lovibond e Lovibond. Psychologica, 36, 235-246.

Parker, G. (1983). Parental overprotection: A risk factor in psychosocial development. New York: Grune and Stratton.

Perris, C. (1994). Linking the experience of dysfunctional parental rearing with manifest psychopathology: A theoretical framework. In C. Perris, W. A. Arrindell, \& M. Eisemann (Eds.), Parenting and psychopathology. Chichester: Wiley.

Pinto-Gouveia, J., \& Matos, M. (2011). Can shame memories become a key to identity? The centrality of shame memories predicts psychopathology. Applied Cognitive Psychology, 25(2), 281-290. doi: 10.1002/acp.1689 
Preacher, K. J., \& Leonardelli, G. J. (2010). Calculation for the Sobel test: An interactive calculation tool for mediation tests. Retrieved from http://www.people.ku.edu/ preacher/sobel/sobel.html

Price, J., Sloman, L., Gardner, R., Gilbert, P., \& Rohde, P. (1994). The social competition hypothesis of depression. British Journal of Psychiatry, 164, 309-315. doi: http://dx.doi.org/10.1192/bjp.164.3.309

Rector, N. A., Bagby, R. M., Segal, Z. V., Joffe, R. T., \& Levitt, A. (2000). Selfcriticism and dependency in depressed patients treated with cognitive therapy or pharmacotherapy. Cognitive Therapy \& Research, 24, 571-584.

Robinson, J. A. (1996). Perspective, meaning and remembering. In D. C. Rubin (Ed.), Remembering our past: Studies in autobiographical memory (pp. 199-217). Mahwah, NJ: Lawrence Erlbaum Associates.

Robinson, J. A., \& Taylor, L. R. (1998). Autobiographical memory and self-narratives: A tale of two stories. In C. P. Thompson, D. J. Herrmann, D. Bruce, J. D. Read, D. G. Payne, \& M. P. Toglia (Eds.), Autobiographical memory: Theoretical and applied perspectives (pp. 125-143). Mahwah, NJ: Lawrence Erlbaum Associates.

Seligman, M.E.P. (1991). Helplessness: On Depression, Development, and Death. (2nd ed.). New York: W.H. Freeman.

Singer, J. A., \& Salovey, P. (1993). The remembered self-emotion and memory in personality. New York: The Free Press.

Schore, A.N. (1994). Affect regulation and the origin of the self: The neurobiology of emotional development. Hillsdale: N.J. Lawrence Erlbaum.

Schore, A. (1998). Early shame experiences and infant brain development. In P. Gilbert, \& B. Andrews (Eds.), Shame: Interpersonal behavior, psychopathology and culture (pp. 57-77). New York: Oxford University Press. 
Schore, A. (2001). The effects of relational trauma on right brain development, affect regulation and infant mental health. Infant Mental Health Journal, 22, 201-269. doi: http://dx.doi.org/10.1002/1097-0355(200101/04)22:1<201::AIDIMHJ8>3.0.CO;2-9

Sloman, L., Gilbert, P., \& Hasey, G. (2003). Evolved mechanisms in depression: The role and interaction of attachment and social rank in depression. Journal of Affective Disorders, 74, 107-121. doi: http://dx.doi.org/10.1016/S01650327(02)00116-7

Sutin, A. R., \& Robins, R. W. (2008). Going forward by drawing from the past: Personal strivings, personally meaningful memories, and personality traits. Journal of Personality, 76(3), 631-664. doi:10.1111/j.14676494.2008.00499.x

Tangney, J. P., \& Fischer, K. W. (Eds.) (1995). Self-conscious emotions: The psychology of shame, guilt, embarrassment and pride. New York: Guilford.

Teasdale, J. D., \& Cox, S. G. (2001). Dysphoria: Self-devaluative and affective components in recovered depressed and never depressed controls. Psychological Medicine, 31, 1311-1316. doi: http://dx.doi.org/10.1017/S003329170100424X

Tracy, J. L., \& Robins, R. W. (2004). Putting the self into self-conscious emotions: A theoretical model. Psychological Inquiry, 15, 103-125. doi: http://dx.doi.org/10.1207/s15327965pli1502_01

Thompson, R., \& Zuroff, D.C. (1999). Development of self-criticism in adolescent girls: roles of maternal dissatisfaction, maternal coldness and insecure attachment. Journal of youth and adolescence, 28, 197-210.

Whelton, W. J., \& Greenberg, L. S. (2005). Emotion in self-criticism. Personality and Individual Differences, 38, 1583-1595. doi:http://dx.doi.org/10.1016/j.paid.2004.09.024 
Zuroff, D. C., Koestner, R., \& Powers, T. A. (1994). Self-criticism at age 12: A longitudinal study of adjustment. Cognitive Therapy Research, 18, 367-385. doi: http://dx.doi.org/10.1007/BF02357511 
Table 1. Means, standard deviations (SD) and Cronbach's alphas for all subjects $(\mathbf{N}=\mathbf{2 0 4})$.

\begin{tabular}{|c|c|c|c|}
\hline \multirow[b]{2}{*}{ Variables } & \multicolumn{2}{|c|}{ Total $(N=204)$} & \multirow{2}{*}{ Cronbach' $\alpha$} \\
\hline & Mean & SD & \\
\hline \multicolumn{4}{|l|}{ Forms of Self-Criticism (FSCRS) } \\
\hline Inadequate self & 13.35 & 7.94 & .89 \\
\hline Hated self & 1.05 & 1.69 & .86 \\
\hline Self-Criticism Total & 14.41 & 8.83 & .89 \\
\hline \multicolumn{4}{|l|}{ Functions of Self-Criticism (FSCS) } \\
\hline Self-persecuting & 5.36 & 5.76 & .88 \\
\hline \multicolumn{4}{|l|}{ Centrality of shame memory } \\
\hline Centrality of event scale (CES) & 44.85 & 17.88 & .96 \\
\hline \multicolumn{4}{|l|}{ Depression } \\
\hline DASS Depression & 5.19 & 5.48 & .92 \\
\hline \multicolumn{4}{|l|}{ Paranoia } \\
\hline Paranoia (GPS) & 44.39 & 10.37 & .89 \\
\hline
\end{tabular}


Table 2. Correlations (2-tailed Pearson r) between self-criticism, centrality of shame memory, depression symptoms and paranoia $(\mathrm{N}=\mathbf{2 0 4})$.

\begin{tabular}{|c|c|c|c|c|c|}
\hline Variables & $\begin{array}{c}\text { FSCRS } \\
\text { (SC) }\end{array}$ & $\begin{array}{c}\text { FSCRS } \\
(\mathbf{R S})\end{array}$ & FSCS & CES & $\begin{array}{c}\text { DASS } \\
\text { Depression }\end{array}$ \\
\hline FSCRS (RS) & -.09 & & & & \\
\hline FSCS & $.63 * *$ & & & & \\
\hline CES & $.32 * *$ & -.06 & $.33 * *$ & & \\
\hline DASS & $.47 * *$ & $-.27 * *$ & $.40 * *$ & $.26^{* *}$ & \\
\hline \multicolumn{6}{|l|}{ Depression } \\
\hline GPS & $.48 * *$ & -.09 & $.38 * *$ & $.39 * *$ & $.49 * *$ \\
\hline \multicolumn{6}{|c|}{$\begin{array}{l}\text { Note. }{ }^{*} p<.05 .{ }^{* *} p<.01 .{ }^{* * *} p<.001 . \text { FSCRS }=\text { Forms of Self-Criticizing/attacking } \\
\text { and Self-Reassuring Scale; FSCRS(SC) }=\text { Sum of the two forms of self-critical factors } \\
\text { inadequate self plus hated self. FSCRS(RS) = Reassured self; FSCS = sum of the two } \\
\text { functions are self-critical factors self correction plus cell persecution; CES = Centrality of } \\
\text { Event Scale; DASS= Depression, Anxiety and Stress Scales; GPS = General Paranoia } \\
\text { Scale. }\end{array}$} \\
\hline
\end{tabular}


Table 3. Mediator effect of Self-Criticism on the relationship between Centrality of Shame Memory and Depression.

\begin{tabular}{|c|c|c|c|c|c|c|}
\hline \multicolumn{7}{|c|}{ Depression } \\
\hline Testing steps for mediation & $B$ & $S E B$ & $\beta$ & $F$ & Adjusted $R^{2}$ & $\Delta R^{2}$ \\
\hline \multicolumn{7}{|l|}{ Step 1} \\
\hline \multicolumn{7}{|l|}{ Outcome: Depression } \\
\hline \multirow[t]{2}{*}{ Predictor: CES } & .08 & .02 & $.26 * * *$ & & & \\
\hline & & & & $14.82 * * *$ & .06 & .07 \\
\hline \multicolumn{7}{|l|}{ Step 2} \\
\hline \multicolumn{7}{|l|}{ Outcome: Self-criticism (FSCRS) } \\
\hline \multirow[t]{2}{*}{ Predictor: CES } & .16 & .03 & $.32 * * *$ & & & \\
\hline & & & & $22.91 * * *$ & .10 & .10 \\
\hline \multicolumn{7}{|l|}{ Step 3} \\
\hline \multicolumn{7}{|l|}{ Outcome: Depression } \\
\hline Predictor: CES & .04 & .02 & .12 & & & \\
\hline \multirow[t]{2}{*}{ Mediator: Self-criticism (FSCRS) } & .27 & .04 & $.43 * * *$ & & & \\
\hline & & & & $30.75 * * *$ & .23 & .23 \\
\hline \multicolumn{7}{|l|}{ Step 1} \\
\hline \multicolumn{7}{|l|}{ Outcome: Depression } \\
\hline \multirow[t]{2}{*}{ Predictor: CES } & .08 & .02 & $.26 * * *$ & & & \\
\hline & & & & $14.82 * * *$ & .06 & .07 \\
\hline \multicolumn{7}{|l|}{ Step 2} \\
\hline \multicolumn{7}{|l|}{ Outcome: Self-attacking (FSCS) } \\
\hline \multirow[t]{2}{*}{ Predictor: CES } & .11 & .02 & $.33 * * *$ & & & \\
\hline & & & & $24.45 * * *$ & .10 & .11 \\
\hline \multicolumn{7}{|l|}{ Step 3} \\
\hline \multicolumn{7}{|l|}{ Outcome: Depression } \\
\hline Predictor: CES & .05 & .02 & $.15^{*}$ & & & \\
\hline \multirow[t]{2}{*}{ Mediator: Self-attacking (FSCS) } & .34 & .06 & $.35 * * *$ & & & \\
\hline & & & & $21.97 * * *$ & .17 & .18 \\
\hline
\end{tabular}


Table 4. Mediator effect of Self-Criticism on the relationship between Centrality of Shame Memory and Paranoia.

\begin{tabular}{lllllll}
\hline & \multicolumn{5}{c}{ Paranoia } \\
\hline Testing steps for mediation & $B$ & $S E B$ & $\beta$ & $F$ & Adjusted $R^{2}$ & $\Delta R^{2}$ \\
\hline Step 1 & & & & & & \\
Outcome: Paranoia & .22 & .04 & $.39 * * *$ & & & \\
Predictor: CES & & & & $35.57^{* * *}$ & .15 & .15
\end{tabular}

Step 2

Outcome: Self-criticism (FSCRS)

Predictor: CES

$.16 \quad .03 \quad .32 * * *$

$22.91 * * * \quad .10$

Step 3

Outcome: Paranoia

Predictor: CES

$\begin{array}{lll}.15 & .04 & .26 * * *\end{array}$

Mediator: Self-criticism (FSCRS) $\quad .47 \quad .07 \quad .40 * * *$

$41.83 * * *$

.29

\section{Step 1}

Outcome: Paranoia

Predictor: CES

$.22 \quad .04 \quad .39 * * *$

$35.57 * * * \quad .15$

Step 2

Outcome: Self-attacking (FSCS)

Predictor: CES

$.11 \quad .02 \quad .33 * * *$

$24.45 * * * \quad .10$

Step 3

Outcome: Paranoia

Predictor: CES

$\begin{array}{lll}.17 & .04 & .29 * * *\end{array}$

Mediator: Self-attacking (FSCS)

$.52 \quad .12 \quad .29 * * *$

$* p<.05 . * * p<.01 . * * * p<.001$ 